Damien Lesenfants, $\mathrm{PhD}^{*}$

Dina Habbal, PhD* Camille Chatelle, $\mathrm{PhD}$

Caroline Schnakers, $\mathrm{PhD}$

Steven Laureys, MD, $\mathrm{PhD}$

Quentin Noirhomme, $\mathrm{PhD}$

Correspondence to Dr. Lesenfants: damien_lesenfants@brown.edu

\title{
Electromyographic decoding of response to command in disorders of consciousness
}

\section{ABSTRACT}

Objective: To propose a new methodology based on single-trial analysis for detecting residual response to command with EMG in patients with disorders of consciousness (DOC), overcoming the issue of trial dependency and decreasing the influence of a patient's fluctuation of vigilance or arousal over time on diagnostic accuracy.

Methods: Forty-five patients with DOC (18 with vegetative/unresponsive wakefulness syndrome [VS/UWS], 22 in a minimally conscious state [MCS], 3 who emerged from MCS [EMCS], and 2 with locked-in syndrome [LIS]) and 20 healthy controls were included in the study. Patients were randomly instructed to either move their left or right hand or listen to a control command ("It is a sunny day") while EMG activity was recorded on both arms.

Results: Differential EMG activity was detected in all MCS cases displaying reproducible response to command at bedside on multiple assessments, even though only 6 of the 14 individuals presented a behavioral response to command on the day of the EMG assessment. An EMG response was also detected in all EMCS and LIS patients, and 2 MCS patients showing nonreflexive movements without command following at the bedside. None of the VS/UWS presented a response to command with this method.

Conclusions: This method allowed us to reliably distinguish between different levels of consciousness and could potentially help decrease diagnostic errors in patients with motor impairment but presenting residual motor activity. Neurology ${ }^{\circledR}$ 2016;87:2099-2107

\section{GLOSSARY}

CRS-R = Coma Recovery Scale-Revised; $\mathbf{D O C}=$ disorders of consciousness; $\mathbf{E M C S}=$ emergence from minimally conscious state; LIS = locked-in syndrome; $\mathbf{M C S}$ = minimally conscious state; RMS = root mean square; VS/UWS = vegetative state/ unresponsive wakefulness syndrome.

Keystones in the diagnosis of patients recovering from coma are the acquisition of voluntary responses such as command following, distinguishing patients in a vegetative state/unresponsive wakefulness syndrome (VS/UWS; characterized by the recovery of eye opening without awareness of self and environment ${ }^{1-3}$ ) from patients in a minimally conscious state (MCS; characterized by inconsistent, fluctuating but reproducible signs of consciousness $\left.{ }^{4}\right)$. However, patients with disorders of consciousness (DOC) have limited neuromuscular abilities, ${ }^{5,6}$ challenging the detection of behavioral response to command based on visual and tactile feedback, as used in clinical gold standard behavioral scales. An additional limitation of behavioral assessment is its dependence on an examiner's experience and subjectivity. ${ }^{7}$ Recent neuroimaging studies have suggested that $11 \%-33 \%$ of patients behaviorally diagnosed as unresponsive using behavioral scales may actually present brain-related signs of consciousness, ${ }^{8}$ highlighting the need to develop more objective and observer-independent diagnostic tools for this population. In particular, EMG has been proposed for the detection of micromovements that often go unnoticed by an observer at a patient's bedside, but results have been mixed. ${ }^{9,10}$ In the current study, we

\footnotetext{
*These authors contributed equally to this work.

From the School of Engineering and Institute for Brain Science (D.L.), Brown University, Providence, RI; Coma Science Group (D.H., S.L.), GIGA-Research, CHU University Hospital of Liège, Belgium; Laboratory for NeuroImaging of Coma and Consciousness (C.C.), Massachusetts General Hospital, Boston; Department of Neurosurgery (C.S.), UCLA, Los Angeles, CA; and Brain Innovation B.V. and Maastricht University (Q.N.), the Netherlands.

Go to Neurology.org for full disclosures. Funding information and disclosures deemed relevant by the authors, if any, are provided at the end of the article.
} 
aimed to improve the detection of residual muscular activity related to command following using a novel EMG method with single-trial level analysis. Given high non-stationarities in the EMG signal (e.g., artifact) and fluctuations in the level of consciousness or arousal over time, we hypothesized that removing dependence on intertrial consistency in this population could improve detection of volitional response to command.

METHODS Participants. Among all patients admitted to the University Hospital of Liège between 2013 and 2014, 45 patients were included in this study (mean age $40 \pm 15$ years; 30 male). Patients were subcategorized according to the following diagnoses: MCS - encompasses patients without signs of language preservation (i.e., showing only visual pursuit or fixation, object localization or manipulation, localization of noxious stimulation, automatic motor response, or smiling/crying in response to external stimuli) whereas MCS + includes patients showing behavioral responses suggesting language preservation such as command following or intelligible words. ${ }^{11-13}$ Emergence from MCS (EMCS) is characterized by the recovery of functional communication or functional object use. ${ }^{4}$ The locked-in syndrome (LIS), on the other hand, is a state in which the patient is paralyzed but awake and fully conscious. ${ }^{14}$

In our study, 17 patients were diagnosed as being in VS/ UWS, 7 in MCS - , 14 in MCS +, 5 in EMCS, and 2 in LIS. Patient LIS1 was able to perform horizontal head movements and slight movements of the arms. Patient LIS2 had a left hemiplegia but could move his right arm within a normal range of motion. Both showed very little spasticity. Inclusion criteria were (1) at least 28 days postinjury, (2) preserved auditory evoked potentials or presence of auditory startle, and (3) no neuromuscular function blockers and no sedation within the prior 24 hours. Exclusion criteria were (1) a documented history of prior brain injury, (2) a premorbid history of developmental, psychiatric, or neurologic illness resulting in documented functional disability up to the time of the injury, (3) a premorbid history of uncorrected hearing impairments, (4) flaccidity in response to noxious stimulation, and (5) acute illness. Four of these patients were evaluated twice (see table 1). Twenty-three patients had traumatic and 22 patients had nontraumatic etiologies (i.e., stroke, hemorrhage, cardiac arrest, infection, or metabolic disorders). Average duration since insult was $38 \pm 48$ months (range 1 month-18 years; median 14 months). Table 1 summarizes patients' demographic and clinical data. We also included 20 healthy controls (mean age $34 \pm 13$ years; 11 male; see table 2). For this group, exclusion criteria were (1) uncorrected hearing impairments, (2) muscle disease or muscle dysfunction due to an injury, and (3) developmental, psychiatric, or neurologic illness. Spasticity of the upper limbs was evaluated using the Modified Ashworth Scale by a trained physiologist and is reported in table e-1 at Neurology.org along with antispastic medications.

Standard protocol approvals, registrations, and patient consents. The study was approved by the Ethics Committee of the University Hospital of Liège. Each healthy control and each patient's legal representative provided written informed consent.

Behavioral assessment and final diagnosis. Patients' level of consciousness was assessed by a trained examiner using the Coma
Recovery Scale-Revised (CRS-R) on the day of the EMG recording and several times during the week to increase diagnostic accuracy. ${ }^{15}$ The best score obtained during the week was used as the final diagnosis.

Paradigm. Three different instructions (recorded using a neutral male voice) were presented to the participants: 2 target instructions (i.e., "Move your left hand" and "Move your right hand") and 1 control instruction (i.e., "It is a sunny day"). Each instruction was presented 3 times in a row within a trial. Each trial lasted 21 seconds, including the instructions ( 3 seconds). A block of stimulation consisted of 3 minutes of rest followed by 5 trials of each instruction randomly presented with an intertrial interval of 10 seconds (about 10 minutes in total) (figure 1). Each participant completed a total of 3 blocks with breaks of varied duration, depending on level of fatigue.

Signal acquisition. Left and right upper limb electrical activity of the abductor policis brevis muscle (channel "Hand") and the flexor digitorum superficialis muscle (channel "Arm") was recorded at the bedside with $8 \mathrm{Ag} / \mathrm{AgCl}$ self-adhesive surface electrodes, placed in a bipolar derivation with an interelectrode distance of $20 \mathrm{~mm}$, sampled at $500 \mathrm{~Hz} \cdot{ }^{16,17}$ Electrodes were connected to a portable BrainVision vAmp amplifier. Data were acquired and auditory instructions presented using a laptop running the general-purpose software platform BCI2000. ${ }^{18}$

Data analysis. The EMG signals were filtered with a zero-phase fourth-order bandpass Butterworth filter (IIR, fc $=20-120 \mathrm{~Hz}$ ) and a second-order notch filter (IIR, fc $=50 \mathrm{~Hz}, \mathrm{Q}=35$ ). We then computed the root mean square (RMS) of 1-second overlapping ( $90 \%$ overlap) windows, occurring between the beginning of the 2-second and end of the 3-second following the presentation of each instruction within a trial (see gray area in figure 1), resulting in 33 windows for each trial and each location.

For each location, we then extracted the difference $\left(\Delta_{\text {active }}\right)$ between averaged RMS value during the trial and the preceding intertrial interval. The difference $\left(\Delta_{\text {rest }}\right)$ between averaged RMS value was also evaluated on consecutive overlapping windows during baseline (1-second window, 90\% overlap; interwindow distance and length were chosen to match those used for $\left.\Delta_{\text {active }}\right)$. Mean $\left(\mu \Delta_{\text {rest }}\right)$ and SD $\left(\sigma \Delta_{\text {rest }}\right)$ of the RMS difference during baseline were then used to set the threshold equal to $\mu \Delta$ rest $+2.6 \sigma \Delta$ rest, which corresponded to detecting an unexpected event with a $p$ value of 0.01 if the data were normally distributed. We considered a positive activation during a trial if at least 1 of the 2 ipsilateral locations exceeded the respective threshold, i.e., $\Delta_{\text {active_arm_ipsilateral }}>\mathrm{T}_{\text {arm_ipsilateral }}$ or $\Delta_{\text {active_hand_ipsilateral }}>\mathrm{T}_{\text {han- }}$ d_ipsilateral. We considered a control trial (placebo) as positive if $\Delta_{\text {active }}$ at one of the 4 locations exceeded threshold.

We hypothesized that an increase in EMG activity during commands "Move your right hand" and "Move your left hand" could be observed in conscious patients while absent in unconscious VS/UWS patients. Because of the patients' clinical condition, we did not expect an EMG response to all commands, but hypothesized a difference in the ratio between response to commands "Move your right/left hand" and control command "It is a sunny day"; this ratio could be used to distinguish volitional response to command from reflexive, spastic, or involuntary movements. We computed an EMG score defined by $(\mathrm{L}+\mathrm{R}) /$ $(C+1)$, with $L$ and $R$ being the number of positive activations detected during left and right command, respectively, and $\mathrm{C}$ being the number of wrongly positive activations during the control condition. By including the control condition, the score takes into account the number of false-positives observed. We then defined a threshold for response (vs no response) to 
Table 1 Demographic, clinical, and task-related data of the patient sample

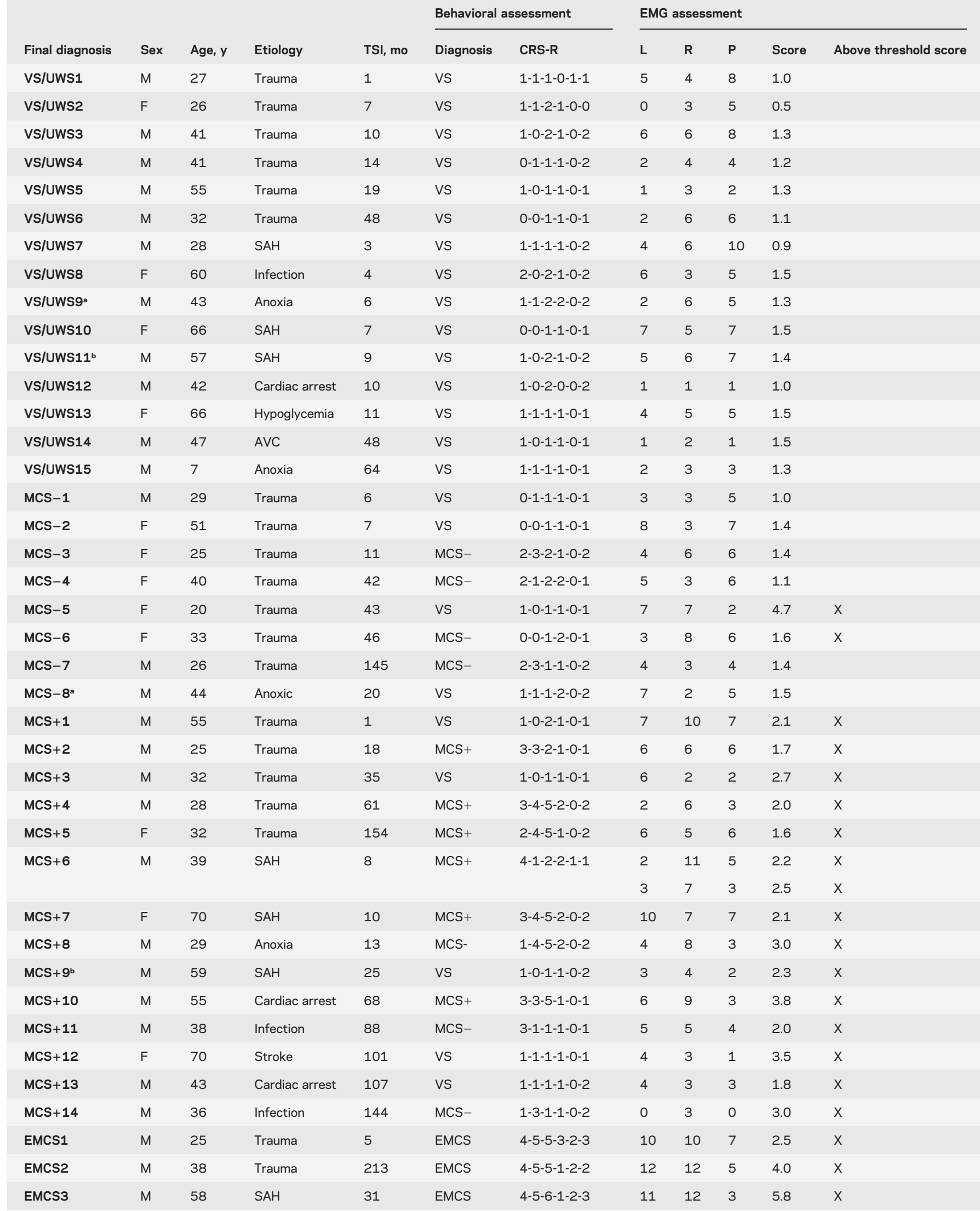

Continued 
Table 1 Continued

\begin{tabular}{|c|c|c|c|c|c|c|c|c|c|c|c|}
\hline Final diagnosis & Sex & Age, $y$ & Etiology & TSI, mo & \multicolumn{2}{|c|}{ Behavioral assessment } & \multicolumn{5}{|c|}{ EMG assessment } \\
\hline LIS1 & $\mathrm{F}$ & 36 & Stroke & 37 & LIS & NA & 9 & 12 & 5 & 3.5 & $\mathrm{x}$ \\
\hline LIS2 & $M$ & 52 & BAO & 5 & LIS & NA & 5 & 12 & 3 & 4.3 & $x$ \\
\hline
\end{tabular}

Abbreviations: $\mathrm{BAO}=$ basilar artery thrombosis; CRS-R = Coma Recovery Scale-Revised; EMCS = emergence from minimally conscious state; LIS = locked-in syndrome; MCS = minimally conscious state; $\mathrm{SAH}=$ subarachnoid hemorrhage; $\mathrm{TSI}$ = time since insult; $\mathrm{VS} / \mathrm{UWS}=$ vegetative state/unresponsive wakefulness syndrome.

Behavioral assessment columns indicate the CRS-R subscores at the day of the EMG assessment for auditory, visual, motor, verbal, communication, and arousal functions, respectively, and related diagnosis. EMG assessment columns illustrate the number of positive activations during "Move your left hand" (column L), "Move your right hand" (column R), and "It is a sunny day" (column P) commands. Column score indicates the EMG score. The last column indicates EMG scores above threshold, illustrating a detected response to command with EMG.

${ }^{a, b}$ Four of these patients were evaluated twice.

command using a leave-one-out cross-validation analysis. Since we first wanted to validate this technique on patients with a more stable diagnosis/level of consciousness, VS/UWS and MCS - in an acute/subacute stage ( $<1$ year post insult) were excluded for this analysis. The defined threshold was nevertheless used afterwards to detect response to command in this excluded group.

\begin{tabular}{|c|c|c|c|c|c|c|c|}
\hline \multirow[t]{3}{*}{ Table 2} & \multicolumn{7}{|c|}{ Demographic and task-related data of the healthy control sample } \\
\hline & \multirow[b]{2}{*}{ Sex } & \multirow[b]{2}{*}{ Age, y } & \multicolumn{5}{|c|}{ EMG assessment } \\
\hline & & & $\mathbf{L}$ & $\mathbf{R}$ & $\mathbf{P}$ & Score & $\begin{array}{l}\text { Above threshold } \\
\text { score }\end{array}$ \\
\hline HV1 & M & 27 & 15 & 15 & 1 & 15.0 & $\mathrm{X}$ \\
\hline HV2 & $\mathrm{F}$ & 36 & 15 & 15 & 0 & 30.0 & $\mathrm{X}$ \\
\hline HV3 & $\mathrm{F}$ & 31 & 15 & 15 & 2 & 10.0 & $x$ \\
\hline HV4 & $M$ & 29 & 15 & 13 & 2 & 9.3 & $x$ \\
\hline HV5 & $M$ & 26 & 15 & 13 & 1 & 14.0 & $x$ \\
\hline HV6 & $M$ & 36 & 15 & 15 & 5 & 5.0 & $x$ \\
\hline HV7 & $\mathrm{F}$ & 14 & 15 & 15 & 1 & 15.0 & $x$ \\
\hline HV8 & $M$ & 56 & 15 & 14 & 4 & 5.8 & $x$ \\
\hline HV9 & $M$ & 33 & 15 & 14 & 1 & 14.5 & $x$ \\
\hline HV10 & $\mathrm{F}$ & 23 & 15 & 15 & 4 & 6.0 & $x$ \\
\hline HV11 & $M$ & 39 & 15 & 15 & 2 & 10.0 & $x$ \\
\hline HV12 & $M$ & 72 & 15 & 15 & 6 & 4.3 & $x$ \\
\hline HV13 & $\mathrm{F}$ & 29 & 15 & 15 & 0 & 30.0 & $x$ \\
\hline HV14 & $\mathrm{F}$ & 24 & 15 & 15 & 4 & 6.0 & $x$ \\
\hline HV15 & $\mathrm{F}$ & 26 & 15 & 15 & 0 & 30.0 & $x$ \\
\hline HV16 & $\mathrm{F}$ & 31 & 11 & 13 & 6 & 3.4 & $x$ \\
\hline HV17 & $M$ & 29 & 15 & 15 & 2 & 10.0 & $x$ \\
\hline HV18 & M & 45 & 15 & 14 & 1 & 14.5 & $x$ \\
\hline HV19 & $\mathrm{F}$ & 37 & 15 & 15 & 1 & 15.0 & $x$ \\
\hline HV2O & $M$ & 29 & 15 & 15 & 0 & 30.0 & $x$ \\
\hline
\end{tabular}

EMG assessment columns illustrate the number of positive activations during "Move your left hand" (column L), "Move your right hand" (column R), and "It is a sunny day" (column P) commands. Column score indicates the EMG score. The last column indicates EMG scores above threshold, illustrating a detected response to command with EMG.
Highest bin count of threshold histogram was selected as the best threshold. In the following, a score higher than 1.5 was considered to be representative of a response to command.

RESULTS From an initial cohort of 45 patients with DOC, 5 were excluded due to high levels of agitation throughout the evaluation, fluctuation in signal due to poor electrode contact, or highly noisy signal in more than a third of the signal. The final cohort consisted of 40 patients (mean age $41 \pm 15$ years; 27 male): 15 VS/ UWS, 7 MCS-, 13 MCS+, 3 EMCS, and 2 LIS.

Behavioral evaluation of response to command. A reproducible response to command was detected in $6 / 14$ MCS+, 3/3 EMCS, and 2/2 LIS with the CRS-R performed on the day of the EMG evaluation. No response to command was detected on the day of the EMG assessment with the CRS-R in the VS/UWS and the MCS - groups.

EMG-based evaluation of response to command. EMG allowed us to detect a response to command in all healthy controls at a single-subject level (see table 2). Mean detected command was 14.8 (left), 14.6 (right), and 2.0 (control) out of 15, corresponding to a mean EMG score of 14 .

At a single-subject level, the method could detect a response to command in 14/14 MCS+, 3/3 EMCS, and 2/2 LIS. The RMS signal of patient EMCS3 is shown in figure $2 \mathrm{~A}$. Two out of the 8 MCS - patients also illustrated a response to command with the EMG at a single-subject level (see table 1). No reproducible response to command was detectable behaviorally, based on the weekly CRS-R evaluation performed in these patients. The RMS signal of patient MCS -5 is shown in figure $2 \mathrm{~B}$.

At a group level, an activation was detected on average: for the VS/UWS patients, 3.2 (left), 4.2 (right), and 5.1 (control), corresponding to a mean EMG score of $1.2 \pm 0.3$; for the MCS - patients, 


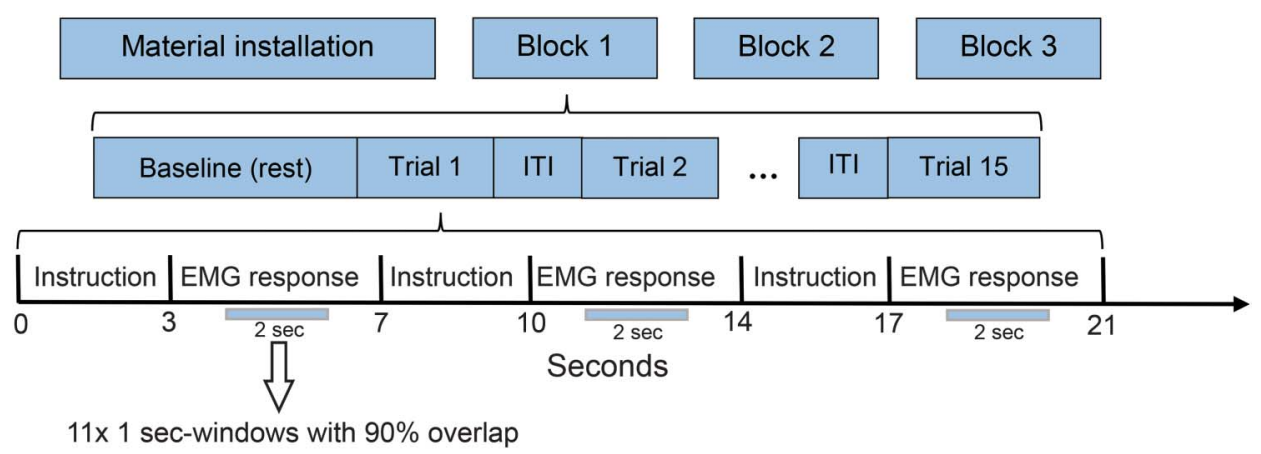

The session was composed of 3 blocks, and each block consisted of 3 minutes recording at rest (baseline) followed by 15 trials. Each trial began with auditory presentation of the task instructions. Then, the EMG response to the command/control was collected. The instruction was repeated 3 times within a trial. Rest EMG activity was recorded during the 10-second intertrial interval (ITI).

5.1 (left), 4.4 (right), and 5.1 (control), corresponding to a mean EMG score of $1.8 \pm 1.1$; for the MCS+ patients, 4.5 (left), 5.9 (right), and 3.7 (control), corresponding to a mean EMG score of $2.4 \pm$ 0.6; for the EMCS patients, 11.0 (left), 11.3 (right), and 5.0 (control), corresponding to a mean EMG score of $4.1 \pm 1.3$; for the LIS patients, 8.0 (left), 13.0 (right), and 3.7 (control), corresponding to a mean EMG score of $4.7 \pm 1.2$. Figure 3 illustrates the boxplot of the different groups.

Robustness and diagnosis evolution. Four of the $40 \mathrm{pa}-$ tients were assessed twice. LIS1 was evaluated twice the same day (morning/afternoon) and showed a response to command in both sessions. VS/ UWS11, VS/UWS9, and MCS+6 were evaluated, respectively, 14, 16, and 11 months after the first evaluation. MCS +6 was MCS + during the 2 evaluations, and this was correctly detected by EMG at each evaluation. VS/UWS11 evolved into an MCS+ (see MCS +9 in table 1). His EMG score increased from 1.4 to 2.3 with this change in level of consciousness, and a response to command was detected by EMG on his second evaluation, while the CRS-R evaluation was not able to detect a response to command the day of the assessment. VS/UWS9 evolved into an MCS- (see MCS -8 in table 1). The EMG score was below threshold during both evaluations.

DISCUSSION The present study confirms the interest in EMG for the detection of responses to command in severely brain-injured patients. The proposed methodology allowed detection of a response to command in all MCS $+(\mathrm{n}=14)$ patients included in this study, while the behavioral evaluation performed on the day of the EMG assessment only allowed detection in 6 out of the 14 MCS+ patients. All EMCS $(\mathrm{n}=3)$ and LIS $(\mathrm{n}=2)$ patients also presented a response to command as assessed by EMG. It is important to note that LIS patients in our study were in an incomplete LIS, meaning they showed residual motor abilities. Patients in a classical or complete LIS, with complete cerebromedullospinal disconnection, would not present a response to command with our method.

Previous EMG studies were tested on a limited number of MCS patients ${ }^{9}(n=2)$ or illustrated a high false-negative rate ${ }^{10}$ (3 detections of response to command out of 20 MCS+ patients; 85\%). Falsenegatives have also been observed in several neuroimaging (range 50\%-67\%) (19,20 $^{20}$ and electrophysiology studies (range $22 \%-100 \%),{ }^{21-25}$ using imagery or topdown modulation of attention (for a review, see Ref. $8,26)$. On the contrary, our paradigm is less cognitively demanding and easier to perform. Indeed, the participant is instructed to perform a movement, not to imagine a movement ${ }^{19,20,22,27}$ or pay attention to a sound. ${ }^{21,23-25}$ In addition, in comparison to previous EMG studies, ${ }^{9,10}$ the increased number of trials and the evaluation of the response to the command on each side (left and right) gives more power to detect reproducible willful motor response and to exclude any random motor activity in this population with severe motor impairments and vigilance fluctuations. ${ }^{28,29}$

No patients with VS/UWS $(\mathrm{n}=15)$ but 2 patients in MCS $-(\mathrm{n}=8)$ presented a response to command with the EMG. While volitional brain activity has previously been found in patients considered in VS/UWS or MCS -, 19,20,23,26,30,31 we do not pretend that the detection of response to command with our EMG paradigm in behaviorally nonresponsive patients reflects a higher level of consciousness. They may be false-positives. Patient MCS -5 only showed inconsistent behavioral signs of consciousness (i.e., visual pursuit during 1 out of 5 behavioral evaluations, the remaining assessments concluding to a VS/UWS). 
Figure 2 Evolution of root mean square (RMS) EMG signal (lower) and $\triangle$ active (upper), i.e., the difference between averaged RMS value during the trial and the preceding intertrial interval, within a block at right arm for patient EMCS3 and at right hand for patient MCS-5

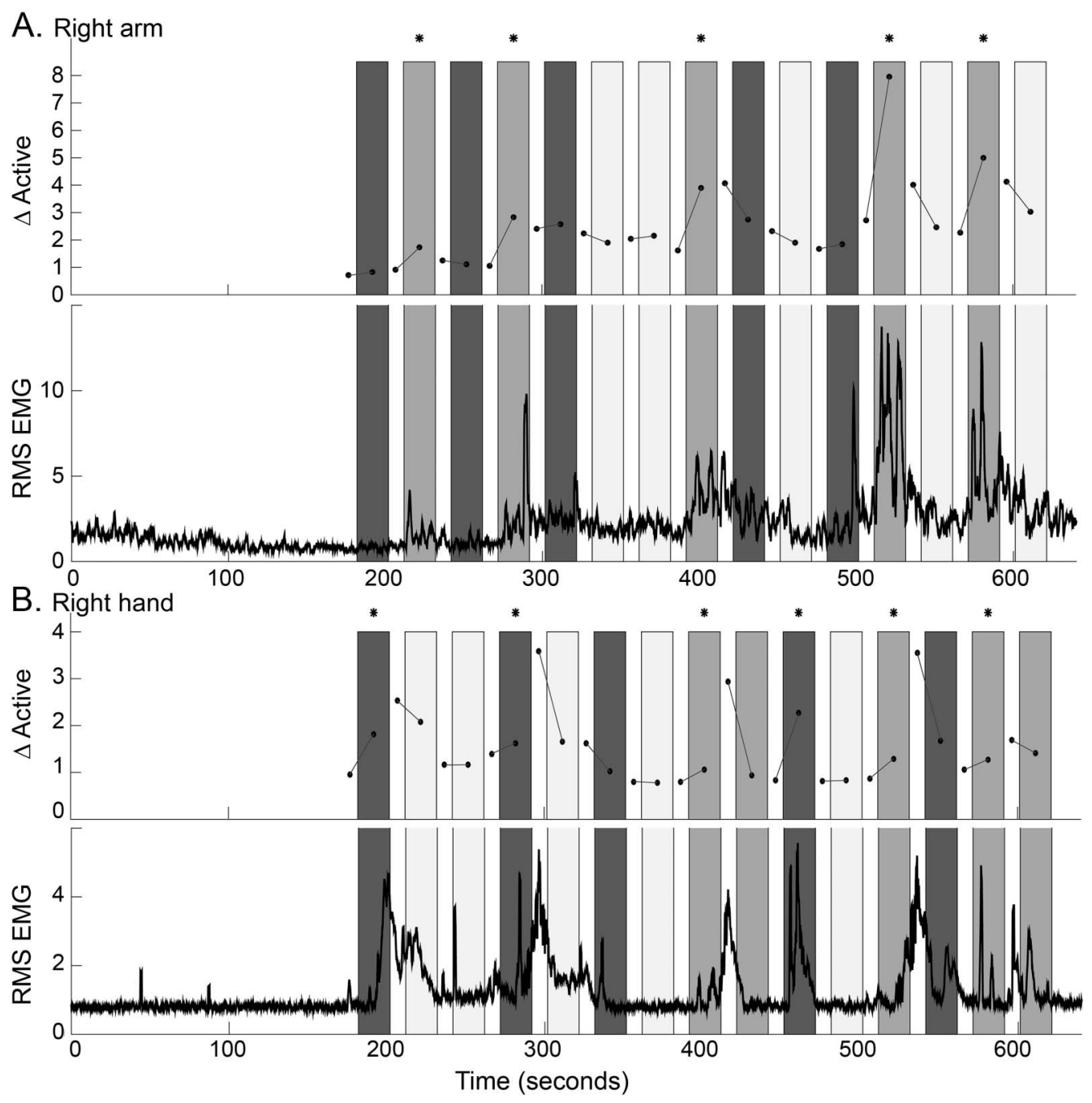

(A) Patient EMCS3. (B) Patient MCS-5. Light gray represents control trials; medium and dark gray represent right and left target commands, respectively. An asterisk above a trial illustrates a positive activation at the corresponding location, i.e., the difference between the EMG activity during the trial and the previous intertrial interval is significantly higher (threshold set at $p=0.01$ ) than baseline fluctuations. Note the positive activation of all 5 right target trials and none of the control trial for patient EMCS3 and 6 target trials ( 3 "right" and 3 "left") and none of the control trial for patient MCS -5.

MRI and fluorodeoxyglucose-PET confirmed the diagnosis of MCS. The patient returned to her home country and did not show much improvement according to her treating physician. Patient MCS -6 died of a cardiopulmonary arrest 8 days following the EMG evaluation. In our study, the EMG score threshold determination was based on leave-one-out cross-validation on the patients with a more stable diagnosis/level of consciousness ( $>1$ year postinjury). A receiver operating characteristic curve analysis led to the determination of the same threshold (area under the curve 1). Using the whole dataset led to a slightly higher threshold of 1.6 (area under the curve $0.96)$, removing patients MCS -6 and MCS +5 from responders' cohort. Multiple patient testing on an extended cohort would better assert the reliability of the used threshold and results.

Evaluating the presence of a response to command on a single trial basis allows to test the performance and signal fluctuation across time, particularly relevant in this population presenting nonstationarities in brain response (e.g., fluctuation of arousal and consciousness) and signal (e.g., artifact, noise). Differential EMG response on spatially close recording locations and on temporally close period of time (trial vs pretrial), as well as use of baseline activity as a reference, also allow to reduce the effect of nonstationarities. However, the proposed approach detected responses to the control instruction ("It is a sunny day") at a single-trial level in majority of the patients. 


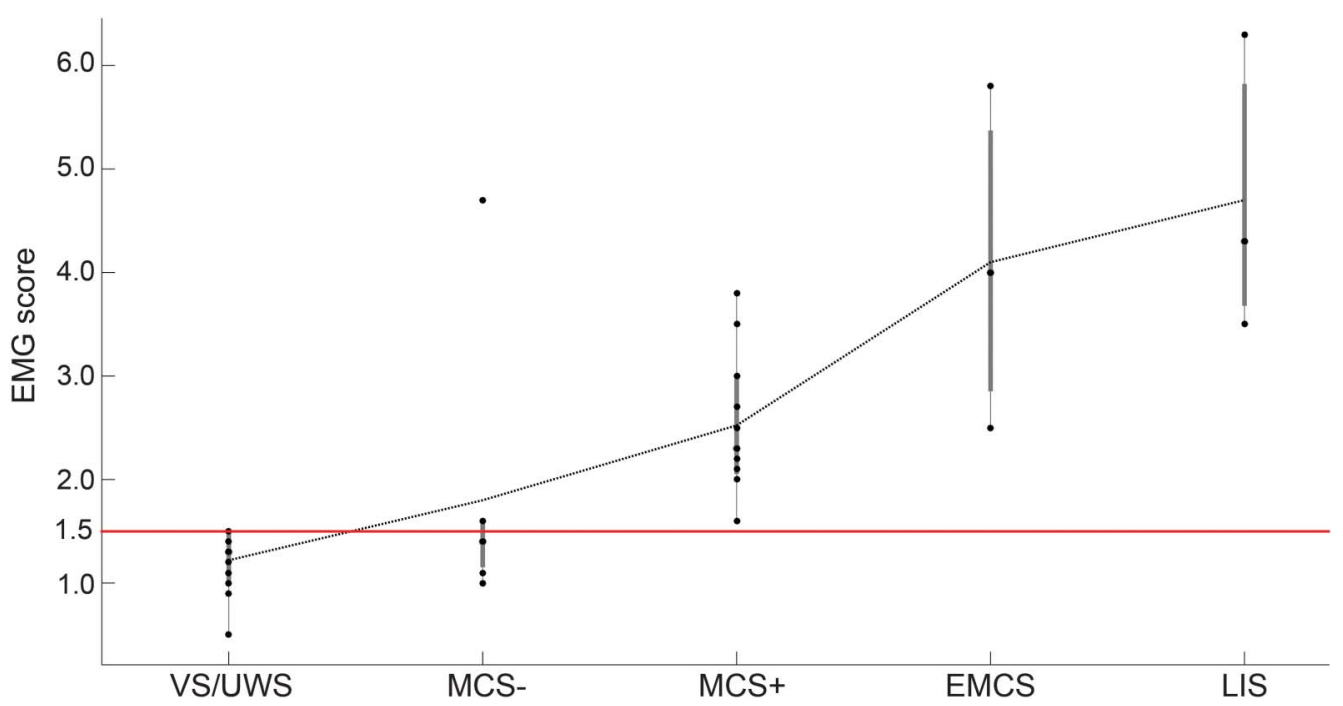

Each dot represents a patient from the respective group. The dashed black line represents the mean EMG score. The horizontal line illustrates the threshold. Note the linear increase of EMG score with an increased level of consciousness and the presence of a response to command in all minimally conscious state plus (MCS + ), emergence from minimally conscious state (EMCS), and locked-in syndrome (LIS), as well as in 2 of 8 MCS-. VS/UWS = vegetative state/unresponsive wakefulness syndrome.

These may be due to patients' spasticity, which is common in this population and could make EMG assessment and interpretation challenging. It is important to note that the $3 \mathrm{MCS}+$ patients with an EMG score lower than 2 illustrated the higher spasticity scores (table e-1), which could explain the difficulty of our methodology to detect an answer. A better model of EMG at rest could improve the single trial detection and enable the translation to EMGbased real-time communication.

Although the results illustrate the interest of our method and suggest that these tools may provide bedside detection of command following, several limitations could hamper its successful applicability in this clinical setting. First, the preservation of some residual voluntary muscle is a condicio sine qua non, preventing its use with patients with complete paralysis. Motor-independent active paradigms relying on functional neuroimaging (e.g., brain-computer interfaces) could represent an interesting alternative in these specific cases. As an illustration, 30 out of the 40 patients were selected to test a motor imagery fMRI-based paradigm $^{19}$ but only one of them illustrated a response to command with this paradigm (VS/UWS3); 25 of them presented head movement preventing interpretable data acquisition (see table e-1). The PET examination of patient VS/UWS3 also illustrated active brain regions similar to an MCS patient. The patient, however, did not respond to command with our EMG paradigm. This could be due to motor paralysis or lack of awareness at the time of the test. Alternatively, patient LIS2 tested an EEG-based motor imagery paradigm during her stay in our hospital and obtained
85\% accuracy. Future studies should also evaluate the effect of neuromuscular weakness on the performance of the proposed method and compare classification obtained during motor-based active task using a multimodal EMG, fMRI, or EEG approach. Second, the success of this paradigm relies on the patient's understanding of the instructions, ability to follow the command and motivation, which might be decreased in case of language or memory impairments, ${ }^{32}$ dysexecutive syndrome such as akinetic mutism $^{33}$ or perseveration, posttraumatic agitation (often associated with delirium), ${ }^{34}$ hypoarousal cause by sedating medication, ${ }^{4}$ or loss of motivation. ${ }^{35,36}$

The proposed EMG-based paradigm allows a 40-minute (which is around the time of a CRS-R assessment) bedside evaluation of response to command using only a few EMG electrodes, an amplifier, and a computer to present the stimuli and record and analyze the signal. Moreover, the paradigm is independent of the examiner's experience or subjectivity. ${ }^{7}$ The results presented in this article were obtained using a single session and may benefit from repetitive evaluation within the week, as is the case with the CRS-R. The potential use of the presented system as a communication tool in the severely brain-injured population should be investigated in the future.

\section{AUTHOR CONTRIBUTIONS}

D.L. and D.H. obtained data and wrote the manuscript. D.L. and Q.N. analyzed and interpreted the data. D.L., D.H., C.C., C.S., S.L., and Q.N. designed the protocol. C.C., C.S., Q.N., and S.L. contributed to the writing of the manuscript. D.L., Q.N., and S.L. were the main investigators. All authors were involved in editing the paper and approved the final text. 


\section{ACKNOWLEDGMENT}

The authors thank the Neurology Department staff of the University Hospital of Liège and the participants and their families for their collaboration.

\section{STUDY FUNDING}

Supported by the National Funds for Scientific Research (FNRS), European ICT Programme Projects FP7-247919 DECODER, James McDonnell Foundation, French Speaking Community Concerted Research Action, and University of Liege. The funders had no role in study design, data collection and analysis, decision to publish, or preparation of the manuscript. D.L., D.H., C.C., C.S., S.L., and Q.N. had full access to all the data in the study, and the corresponding author had final responsibility for the decision to submit for publication.

\section{DISCLOSURE}

The authors report no disclosures relevant to the manuscript. Go to Neurology.org for full disclosures.

Received February 10, 2016. Accepted in final form July 29, 2016.

\section{REFERENCES}

1. The Multi-Society Task Force on PVS. Medical aspects of the persistent vegetative state (1). N Engl J Med 1994; 330:1499-1508.

2. Laureys S, Celesia G, Cohadon F, et al. Unresponsive wakefulness syndrome: a new name for the vegetative state or apallic syndrome. BMC Med 2010;8:68.

3. von Wild K, Laureys S, Gerstenbrand F, Dolce G, Onose G. The vegetative state: a syndrome in search of a name. J Med Life 2012;5:3-15.

4. Giacino JT, Ashwal S, Childs N, et al. The minimally conscious state: definition and diagnostic criteria Neurology 2002;58:349-353.

5. Laureys S, Perrin F, Schnakers C, Boly M, Majerus S. Residual cognitive function in comatose, vegetative and minimally conscious states. Curr Opin Neurol 2005; 18:726-733.

6. Laureys S, Schiff ND. Coma and consciousness: paradigms (re)framed by neuroimaging. Neuroimage 2012 ; 61:478-491.

7. Lovstad M, Froslie KF, Giacino JT, Skandsen T, Anke A, Schanke AK. Reliability and diagnostic characteristics of the JFK coma recovery scale-revised: exploring the influence of rater's level of experience. J Head Trauma Rehabil 2010;25:349-356.

8. Noirhomme Q, Brecheisen R, Lesenfants D, Antonopoulos G, Laureys S. "Look at my classifier's result": disentangling unresponsive from (minimally) conscious patients. Neuroimage 2015;8119:01119-1122.

9. Bekinschtein TA, Coleman MR, Niklison J, Pickard JD, Manes FF. Can electromyography objectively detect voluntary movement in disorders of consciousness? J Neurol Neurosurg Psychiatry 2008;79:826-828.

10. Habbal D, Gosseries O, Noirhomme Q, et al. Volitional electromyographic responses in disorders of consciousness. Brain Inj 2014;28:1171-1179.

11. Bruno MA, Vanhaudenhuyse A, Thibaut A, Moonen G, Laureys S. From unresponsive wakefulness to minimally conscious plus and functional locked-in syndromes: recent advances in our understanding of disorders of consciousness. J Neurol 2011;258:1373-1384.

12. Bruno MA, Majerus S, Boly M, et al. Functional neuroanatomy underlying the clinical subcategorization of minimally conscious state patients. J Neurol 2012; 259:1087-1098.
13. Giacino JT, Edlow B, Chatelle C, Schnakers C. The minimally conscious state: clinical features, pathophysiology and therapeutic implications. In: Laureys S, Tononi G, Gosseries O, eds. The Neurology of Consciousness, 2nd ed. Cambridge, MA: Academic Press; 2016.

14. Laureys S, Pellas F, van Eeckhout P, et al. The locked-in syndrome: what is it like to be conscious but paralyzed and voiceless? Prog Brain Res 2005;150:495-511.

15. Giacino JT, Kalmar K, Whyte J. The JFK Coma Recovery Scale-Revised: measurement characteristics and diagnostic utility. Arch Phys Med Rehabil 2004;85:2020-2029.

16. Hugger S, Schindler HJ, Kordass B, Hugger A. Clinical relevance of surface EMG of the masticatory muscles (part 1): resting activity, maximal and submaximal voluntary contraction, symmetry of EMG activity. Int J Comput Dent 2012;15:297-314.

17. Nöjd N, Hannula M, Narra N, Hyttinen J. Electrode position optimization for facial EMG measurements for humancomputer interface. Methods Inf Med 2008;47:192-197.

18. Schalk G, McFarland DJ, Hinterberger T, Birbaumer N, Wolpaw JR. BCI2000: a general-purpose brain-computer interface (BCI) system. IEEE Trans Biomed Eng 2004;51: 1034-1043.

19. Monti MM, Vanhaudenhuyse A, Coleman MR, et al. Willful modulation of brain activity in disorders of consciousness. N Engl J Med 2010;362:579-589.

20. Stender J, Gosseries O, Bruno MA, et al. Diagnostic precision of PET imaging and functional MRI in disorders of consciousness: a clinical validation study. Lancet 2014; 384:514-522.

21. Goldfine AM, Victor JD, Conte MM, Bardin JC, Schiff ND. Determination of awareness in patients with severe brain injury using EEG power spectral analysis. Clin Neurophysiol 2011;122:2157-2168.

22. Cruse D, Chennu S, Chatelle C, et al. Relationship between etiology and covert cognition in the minimally conscious state. Neurology 2012;78:816-822.

23. King JR, Faugeras F, Gramfort A, et al. Single-trial decoding of auditory novelty responses facilitates the detection of residual consciousness. Neuroimage 2013;83:726-738.

24. Lulé D, Noirhomme Q, Kleih SC, et al. Probing command following in patients with disorders of consciousness using a brain-computer interface. Clin Neurophysiol 2013;124:101-106.

25. Pokorny C, Klobassa DS, Pichler G, et al. The auditory P300-based single-switch brain-computer interface: paradigm transition from healthy subjects to minimally conscious patients. Artif Intell Med 2013;59:81-90.

26. Chatelle C, Lesenfants D, Guller Y, Laureys S, Noirhomme Q. Brain-computer interface for assessing consciousness in severely brain-injured patients. In: Rossetti AO, Laureys S, eds. Clinical Neurophysiology in Disorders of Consciousness. Vienna: Springer-Verlag Wien; 2015: 133-148

27. Cruse D, Chennu S, Chatelle C, et al. Bedside detection of awareness in the vegetative state: a cohort study. Lancet 2011;378:2088-2094.

28. Thibaut A, Chatelle C, Ziegler E, Bruno MA, Laureys S, Gosseries O. Spasticity after stroke: physiology, assessment and treatment. Brain Inj 2013;27:1093-1105.

29. Nakase-Richardson R, Yablon SA, Sherer M, Nick TG, Evans CC. Emergence from minimally conscious state: insights from evaluation of post-traumatic confusion. Neurology 2009;73:1120-1126. 
30. Schnakers C, Perrin F, Schabus M, et al. Detecting consciousness in a total locked-in syndrome: an active eventrelated paradigm. Neurocase 2009;15:271-277.

31. Chennu S, Finoia P, Kamau E, et al. Dissociable endogenous and exogenous attention in disorders of consciousness. Neuroimage Clin 2013;3:450-461.

32. Majerus S, Bruno MA, Schnakers C, Giacino JT, Laureys S. The problem of aphasia in the assessment of consciousness in brain-damaged patients. Prog Brain Res 2009;177:49-61.

33. Giacino JT. Disorders of consciousness: differential diagnosis and neuropathologic features. Semin Neurol 1997; 17:105-111.
34. Sandel ME, Mysiw WJ. The agitated brain injured patient: part 1: definitions, differential diagnosis, and assessment. Arch Phys Med Rehabil 1996;77:617-623.

35. Kleih SC, Nijboer F, Halder S, Kübler A. Motivation modulates the P300 amplitude during brain-computer interface use. Clin Neurophysiol 2010;121:10231031.

36. Nijboer F, Birbaumer N, Kübler A. The influence of psychological state and motivation on brain-computer interface performance in patients with amyotrophic lateral sclerosis: a longitudinal study. Front Neurosci 2010;4:55.

\section{This Week's Neurology ${ }^{\circledR}$ Podcast}

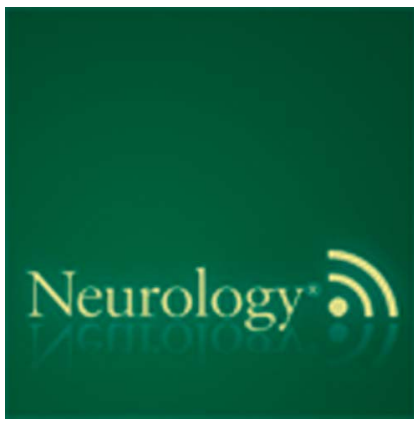

Efficacy and safety of deflazacort vs prednisone and placebo for Duchenne muscular dystrophy (see p. 2123)

This podcast begins and closes with Dr. Robert Gross, Editor-inChief, briefly discussing highlighted articles from the November 15, 2016, issue of Neurology. In the second segment, Dr. Kelly Gwathmey talks with Dr. Robert Griggs about his article on the efficacy and safety of deflazacort versus prednisone for boys with Duchenne muscular dystrophy. Dr. Ilena George reads the e-Pearl of the week about alien limb phenomenon. In the next Dr. Don Gilbert on the topic of tics. part of the podcast, Dr. Alberto Espay focuses his interview with

Disclosures can be found at Neurology.org.

At Neurology.org, click on "RSS" in the Neurology Podcast box to listen to the most recent podcast and subscribe to the RSS feed.

CME Opportunity: Listen to this week's Neurology Podcast and earn 0.5 AMA PRA Category 1 CME Credits ${ }^{\mathrm{TM}}$ by answering the multiple-choice questions in the online Podcast quiz.

\section{Subspecialty Alerts by E-mail!}

Customize your online journal experience by signing up for e-mail alerts related to your subspecialty or area of interest. Access this free service by visiting Neurology.org/site/subscriptions/etoc.xhtml or click on the "E-mail Alerts" link on the home page. An extensive list of subspecialties, methods, and study design choices will be available for you to choose from—allowing you priority alerts to cutting-edge research in your field! 


\section{Neurology}

Electromyographic decoding of response to command in disorders of consciousness Damien Lesenfants, Dina Habbal, Camille Chatelle, et al.

Neurology 2016;87;2099-2107 Published Online before print October 21, 2016

DOI 10.1212/WNL.0000000000003333

This information is current as of October 21, 2016

\begin{tabular}{|c|c|}
\hline $\begin{array}{l}\text { Updated Information \& } \\
\text { Services }\end{array}$ & $\begin{array}{l}\text { including high resolution figures, can be found at: } \\
\text { http://www.neurology.org/content/87/20/2099.full.html }\end{array}$ \\
\hline Supplementary Material & $\begin{array}{l}\text { Supplementary material can be found at: } \\
\text { http://www.neurology.org/content/suppl/2016/10/21/WNL.0000000000 } \\
\text { 003333.DC1 }\end{array}$ \\
\hline References & $\begin{array}{l}\text { This article cites } 34 \text { articles, } 4 \text { of which you can access for free at: } \\
\text { http://www.neurology.org/content/87/20/2099.full.html\#\#ref-list-1 }\end{array}$ \\
\hline Subspecialty Collections & $\begin{array}{l}\text { This article, along with others on similar topics, appears in the } \\
\text { following collection(s): } \\
\text { Brain trauma } \\
\text { http://www.neurology.org//cgi/collection/brain_trauma } \\
\text { Clinical neurology examination } \\
\text { http://www.neurology.org//cgi/collection/clinical_neurology_examinati } \\
\text { on } \\
\text { Coma } \\
\text { http://www.neurology.org//cgi/collection/coma } \\
\text { EMG } \\
\text { http://www.neurology.org//cgi/collection/emg }\end{array}$ \\
\hline Permissions \& Licensing & $\begin{array}{l}\text { Information about reproducing this article in parts (figures,tables) or in } \\
\text { its entirety can be found online at: } \\
\text { http://www.neurology.org/misc/about.xhtml\#permissions }\end{array}$ \\
\hline Reprints & $\begin{array}{l}\text { Information about ordering reprints can be found online: } \\
\text { http://www.neurology.org/misc/addir.xhtml\#reprintsus }\end{array}$ \\
\hline
\end{tabular}

Neurology ${ }^{\circledR}$ is the official journal of the American Academy of Neurology. Published continuously since 1951, it is now a weekly with 48 issues per year. Copyright () 2016 American Academy of Neurology. All rights reserved. Print ISSN: 0028-3878. Online ISSN: 1526-632X.

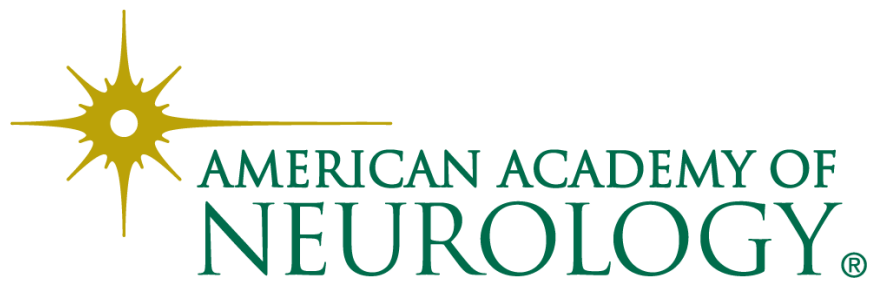

